\title{
Immersive landscapes: modelling ecosystem reference conditions in virtual reality
}

\author{
Tom Chandler $(\mathbb{D} \cdot$ Anna E. Richards • Bernhard Jenny • Fiona Dickson • \\ Jiawei Huang • Alexander Klippel • Michael Neylan • Florence Wang • \\ Suzanne M. Prober
}

Received: 17 March 2021 / Accepted: 3 August 2021 / Published online: 29 October 2021

(C) The Author(s) 2021

\begin{abstract}
Context Understanding the variability and dynamics of ecosystems, as well as their responses to climate or land use change, is challenging for policy makers and natural resource managers. Virtual reality (VR) can be used to render virtual landscapes as immersive, visceral experiences and communicate ecosystem dynamics to users in an effective and engaging way.

Objectives To illustrate the potential and believability of VR, a team of landscape ecologists and
\end{abstract}

Supplementary Information The online version contains supplementary material available at https://doi.org/10.1007/ s10980-021-01313-8.

T. Chandler · B. Jenny · M. Neylan

Faculty of Information Technology, Monash University, 25 Exhibition Walk, Clayton, VIC 3168, Australia e-mail: tom.chandler@monash.edu

A. E. Richards

CSIRO Land and Water, 564 Vanderlin Drive, Berrimah, NT 0828, Australia

F. Dickson

Department of Agriculture, Water and the Environment, John Gorton Building, King Edward Terrace, Parkes,

ACT 2600, Australia

\section{J. Huang}

Department of Geography, Pennsylvania State University, Walker Building, 302 N Burrowes Street, University Park, PA 16802, USA immersive visualisation researchers modelled a reference Australian Box Gum Grassy Woodland landscape, an endangered eucalypt woodland ecosystem that is difficult to observe in its pre-European colonisation form.

Methods We document considerations for designing the immersive virtual landscape, including the creation of animated three-dimensional (3D) plants that alternate between the seasons, and soundscapes that change through the course of a simulated day. We used a heuristic evaluation with experts to assess the potential of immersive VR landscape modeling.

\footnotetext{
A. Klippel $(\square)$

Laboratory of Geo-Information Science and Remote Sensing, Wageningen University \& Research, GAIA building (building 101) Room 310 I Droevendaalsesteeg 3, 6708 PB, Wageningen, Gelderland P.O Box 47, 6700 AA,

Netherlands

e-mail: alexander.klippel@wur.nl

F. Wang

CSIRO Information Management \& Technology,

Research Way, Clayton, VIC 3168, Australia

S. M. Prober

CSIRO Land and Water, Underwood Avenue, Floreat, WA 6014, Australia
} 
Results This cross disciplinary collaboration resulted in a VR experience that was evaluated in a series of meetings by 27 ecologists and managers in biodiversity conservation, many of whom were familiar with Box Gum Grassy Woodlands. 88\% of participants stated that the simulation was believable and participants thought that virtual landscapes held great potential for education, public engagement and land management.

Conclusions Possible future directions include open-source libraries of ecological 3D models, and the visual simulation of historic landscapes and future climate change scenarios.

Keywords Box gum grassy woodland - Ecosystem models · Eucalyptus albens · Virtual reality · Virtual landscape $\cdot$ Virtual ecology $\cdot$ 3D plant models

\section{Introduction}

Biodiversity, ecosystems and natural landscapes around the globe are declining at an alarming rate (Brondizio et al. 2019). Land use and related pressures have already reduced biodiversity intactness beyond critical thresholds across most biomes (Newbold et al. 2016), impacts of climate change are evident in most ecosystems (Scheffers et al. 2016), and the stability of the Earth system is in question (Steffen et al. 2015). Follow-on impacts on economies and societies are predicted around the globe (Pecl et al. 2017). In the context of rapid global change, a systematic approach to articulating changes in ecosystem characteristics effective on-ground management and policy decisions that will sustain and improve the health and wellbeing of the planet's natural and cultural heritage.

Ecosystems consist of biological communities of interacting organisms and their physical environment. They are complex and dynamic across space and time as a result of climatic and edaphic gradients and landscape-scale disturbance and recovery processes, such as fire, flood and cyclone. The disturbance regimes to which ecosystems have evolved over time produce a set of dynamic and impermanent ecosystem attributes that are characteristic of ecosystems in reference condition (Richards et al. 2020). An ecosystem reference displays ecological integrity (Kay 1991; Norton 1992; Kandziora et al. 2013). In the contemporary world, human activity has shifted ecosystems out of reference states. This includes activity such as the clearance of native vegetation, agricultural production practices which alter soil and vegetation, the introduction of invasive pests and weeds, changes to hydrological and fire regimes, as well as human-induced climate change. It has therefore become more challenging to witness and experience ecosystems displaying reference dynamics and conditions.

Here we first describe the potential advantages of immersive VR over traditional box-and-arrow diagrams for expressing the complex dynamics of ecosystems. Second, we briefly discuss the immersive visualisation of ecosystems and overview the threedimensional (3D) geometric modelling of the plants. Third, we evaluate the created immersive experience with domain experts.

\section{Communicating dynamic ecosystem behaviour}

The development of the virtual landscapes described in this paper were first trialled as alternatives to more traditional two-dimensional presentations of information. A common way to communicate ecosystem dynamics is through box-and-arrow style diagrams, sometimes known as dynamic ecosystem models or state-and-transition models (Westoby et al. 1989; Stringham et al. 2003; Bestelmeyer et al. 2017). An example is the Australian Ecosystem Models (AusEcoModels) Framework (Richards et al. 2020), which is a national system of dynamic ecosystem models that aims to consistently describe the natural range of variability found in broadly described, conceptual reference ecosystem states in Australia. The framework currently uses box-and-arrow style diagrams to express ecosystem dynamics in both reference and modified conditions. These diagrams consolidate a significant amount of ecological knowledge, but can be overwhelming and require a considerable amount of effort, even for an experienced ecologist, to interpret. A two-dimensional presentation of information also poses significant challenges for expressing ecosystem dynamics which occur across space and time. For example, dynamics can occur across seasonal, sub-decadal, decadal, millennial and geological timescales and dynamics play out variably over landscapes. Whilst two-dimensional models attempt to squeeze all this variability into a set of ecosystem 
expressions within a dynamic reference state model, they are highly academic and are unlikely to elicit a visceral or emotive response to an ecosystem. As well as supporting effective on-ground and policy decisions, Virtual Reality can engage people who live in increasingly urban environments by creating a visceral or emotive response. Immersive visualizations afforded through augmented and virtual reality (Milgram and Kishino 1994) offer potential solutions to these communication challenges. Immersive technologies provide realistic experiences to the human sensory system that increasingly match actual placebased experiences (Slater and Sanchez-Vives 2016; Wallgrün et al. 2019a). Additionally, they are not bound by many of the same constraints of physical reality. A user of these technologies can adopt perspectives that are difficult to achieve in the real world, such as experiencing remote locations and temporal warps into the past and future (Dede 2009; Zhao and Klippel 2019).

In this article, we showcase a proof-of-concept immersive virtual reality (VR) visualisation of an exemplar dynamic ecosystem model applied to Box Gum Grassy Woodlands that occur in eastern Australia. We use the term virtual ecology to describe the interchange between ecology and virtual technologies. Our work includes temporal, sonic and spatial simulations, and provides a perspective on the utility of immersive VR for:

(1) Building stakeholder empathy and understanding about the values, qualities and characteristics of these ecosystems through enabling users to experience ecosystems, and their dynamic behaviour, in their reference state.

(2) Representing the temporal and spatial dynamics of ecosystems to support a more visceral experience of these complex dynamics.

Geometric three-dimensional modelling and immersive visualisation of ecosystems

This project sought to appraise how a reference Box Gum Grassy Woodland ecosystem state might be perceived, heard, and experienced as a virtual environment. Elements of our proof-of-concept virtual landscape were first constructed with 3D modelling software, then assembled, animated, and augmented with soundscapes inside a game engine, and finally exported as an immersive experience mediated by VR headsets. VR applications that display 3D models of forest trees based on observed or modelled data have been proposed for scientific visualisation and analysis (Fabrika et al. 2018; Huang et al. 2019), and there are also approaches that follow more creative pursuits, modelling the processes of plant morphogenesis to create generative artworks and experimental ecologies (McCormack 2004). The immersive visceral 3D visualisation of ecosystems, including the modelling of specific species, has been explored in marine ecology (Hruby et al. 2019) and landscape visualisation (Huang et al. 2020) and the spatial, embodied, and contextual qualities of VR have been deployed as educational tools for students to learn about natural or human environments (Wallgrün et al. 2019b). In the field of virtual heritage, too, the digital visualisation of past landscapes has necessarily had to accommodate the importance of vegetation confirmed by pollen cores and the examination of plant remains at archaeological sites. The medieval Cambodian capital of Angkor, for example, was distinct among premodern cities as a 'green metropolis' (Chandler and Clulow 2020), and the visualisation of vegetation is crucial to historical visualizations appraising its urban structure and cultural landscapes (Fig. 1b).

Modelling ecosystems is challenging because of the complex and extensive geometries of plants shaped by diverse environmental factors. Geometry reduction methods, such as level of detail algorithms, have been actively researched to reduce the number of geometry polygons and thereby achieve interactive frame rates when rendering the scene (Neubert et al. 2011; Zhang et al. 2017; Kohek and Strnad 2018). Given the interactions between species, it is extremely complex to model ecosystems following biological laws faithfully. The 3D modelling of trees can be traced back to the 1960s with the L-systems developed by Lindenmayer (1968). New digital methods to automatically generate $3 \mathrm{D}$ models of trees have been actively researched in both academia and industry, and there is now a wide spectrum of methods available (Boudon et al. 2006). Today, many 3D forest scenes are created through specialised vegetation 3D modelling software such as SpeedTree, Onyx, $x$ Frog, Marlin Studios and PlantFactory. Often these tree models are deployed in the creation of visually engaging scenes for games and animations, where botanical accuracy is a secondary consideration. Where they support an animated narrative, the artistic stylisation 


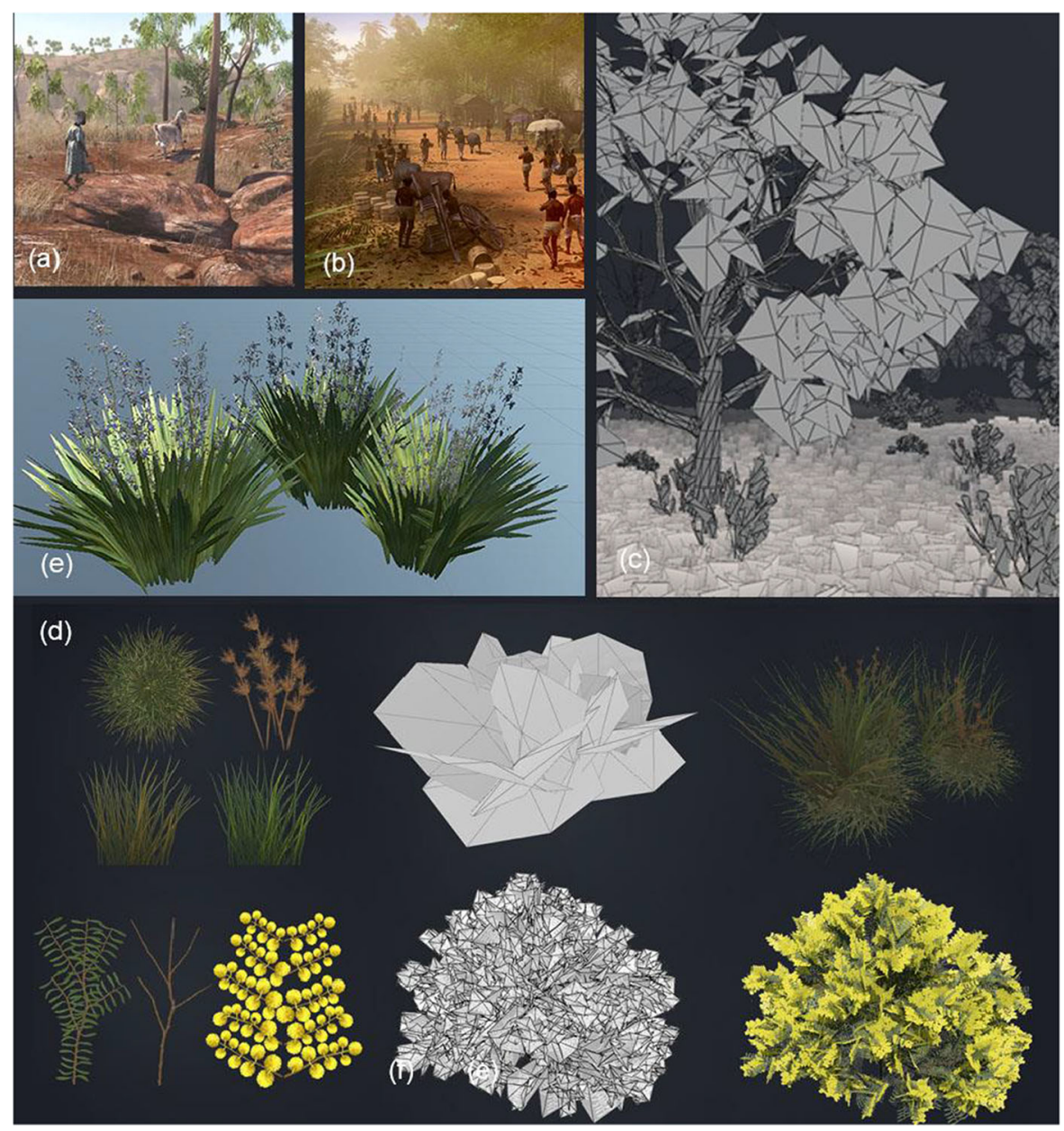

Fig. 1 3D plant models as constituent parts of a virtual landscape and as discrete models. Clockwise from upper lefta a frame from a short animation titled Purdiwan (Pretty One), based upon a kurija (women's fun song) that recalls moving goats from one location to another in the country of the Garrwa people of the Australian Northern Territory (Brent McKee, Monash University, 2011). b a frame from an animation of a

of 3D tree models (Fig. 1a) can convey the ecology of a place more directly; just as cartoonists use exaggeration and caricature to highlight emotional responses and movement.

\section{Methods}

Study system: Box Gum Grassy Woodland

The nationally listed threatened ecological community White Box-Yellow Box-Blakely's Red Gum Grassy thoroughfare in the urban core of medieval Angkor (Monash University, 2018). c wireframe rendering showing the underlying 3D geometry beneath the textured surfaces. $\mathbf{d}$ the textures, 3D geometry and resulting combination of textured geometry in 3D models of Themeda triandra (left to right, upper register), and Acacia decora (left to right, lower register). e textured 3D models of Dianella revoluta (blueberry lily)

Woodland (Environment Protection and Biodiversity Conservation Act 1999, Australia)_herein termed Box Gum Grassy Woodland-was chosen as the focus of the proof-of-concept virtual landscape because of the extensive information available on this woodland ecosystem, including well-established state-and-transition models (Prober et al. 2002, 2014; Prober and Thiele 2005; McIntyre and Lavorel 2007). Box Gum Grassy Woodlands are estimated to have originally been distributed across more than 5 million ha, west of the Great Dividing Range, in four jurisdictions (Queensland, New South Wales, Australian Capital 
Territory, Victoria) of eastern Australia. Extensive past clearing and ongoing land use has seen a decline in their distribution by more than $92 \%$ (Prober and Thiele 2005; Department of Environment 2010). As this ecological community is listed as endangered/critically endangered under both federal and State legislations, there is considerable interest and investment for the ongoing management of these ecosystems to improve their ecological condition.

The dynamic ecosystem model for re-sprouter temperate and subtropical eucalypt woodlands, developed in the AusEcoModels framework (Richards et al. 2020) was used as a template to develop a box-andarrow diagram of a Box Gum Grassy Woodland in a reference state (Fig. 2), here dominated by the White Box species Eucalyptus albens. This reference state included expressions in the dynamic ecosystem model 'eucalypt woodland with a grassy understorey' and 'Eucalypt-Callitris woodland'. To simulate changes over time we conceptualised four virtual scenes for the VR simulation that would communicate the dynamics

(a) Reference state box-andarrow diagram

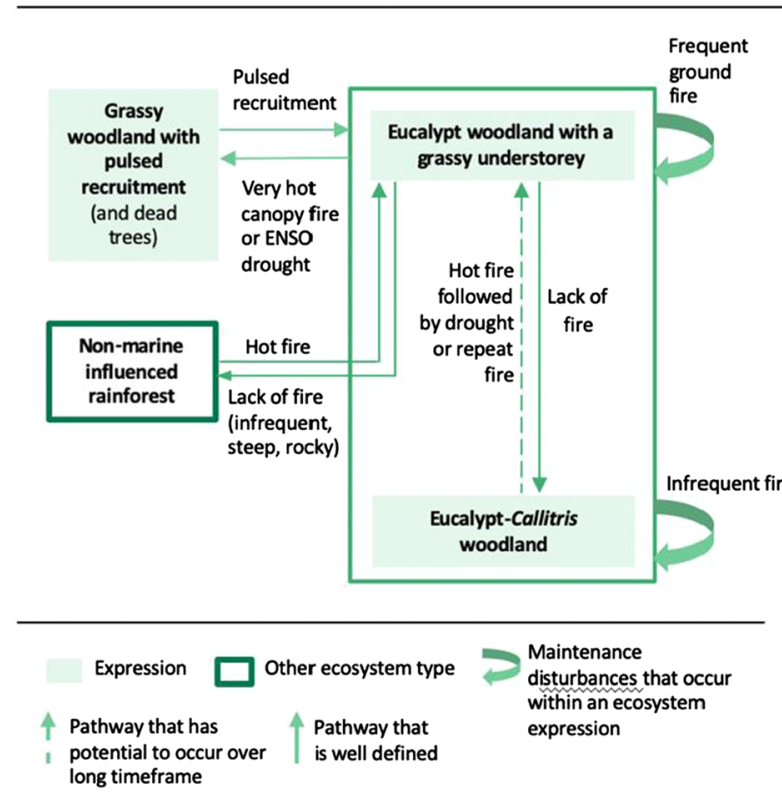

Fig. 2 A reference state model for a White Box (Eucalyptus albens) Gum Grassy Woodland, showing a box and arrow style conceptual dynamic ecosystem model for a 'Re-spouter temperate and subtropical eucalypt woodland' adapted from Richards et al. (2020) and Prober et al. (2021).; b photographic examples of the expressions 'Eucalypt woodland with a grassy understorey' and 'Eucalypt-Callitris woodland' from the field of changes to plant diversity, abundance and ground cover (Prober and Thiele 1995; Prober and Thiele 2005; Cheal 2010; Stol and Prober 2015) captured by these expressions. The scenes were (Fig. 2):

1. Immediate post-fire: this landscape is produced after a patchy, low-intensity fire which would have occurred every 4 years in Box Gum Grassy Woodlands. These fires remove most of the ground cover and leaves from small shrubs but leave the canopy intact. There is extensive bare ground with blackened bases of perennial grass tussocks and black, leafless shrubs remaining. The lower trunks of canopy trees are also black from firing of the bark.

2. Mixed-age woodlands: this landscape occurs approximately 3 to 4 years after fire and assumes there has been sufficient rainfall to stimulate resprouting of grasses and forbs. The ground layer plant diversity is high, with many flowering forbs in spaces between re-generating grass tussocks,

(b) Field examples (photography)

(c) Virtual reality scene

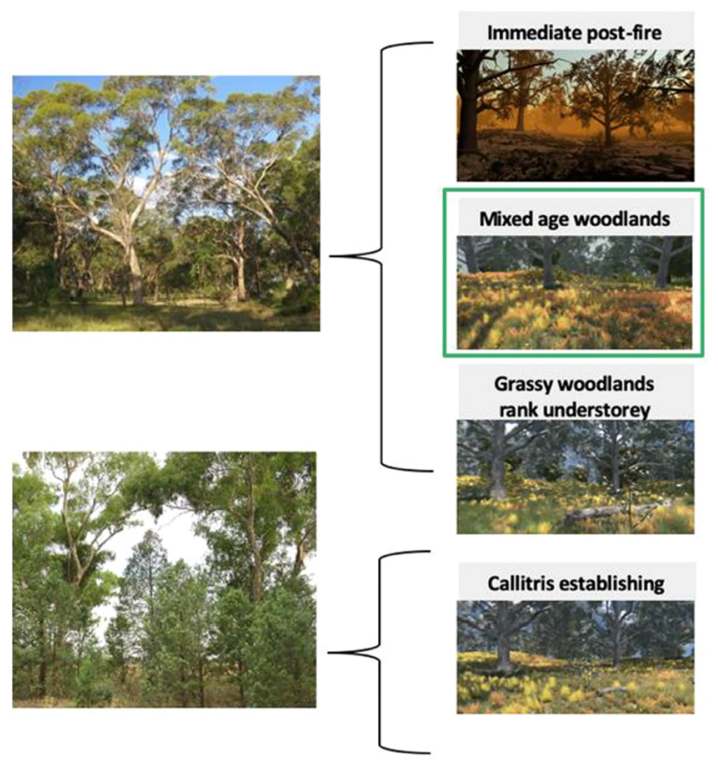

(Photos: S. Prober); and $\mathbf{c}$ an example of the four virtual reality scenes developed in the proof-of-concept virtual landscape, used to depict ecosystem dynamics for the two expressions depicted in the photographs.Seasonal variations of the mixed age woodlands (enclosed in a green box at right) were later evaluated by experts in a VR headset (Fig. 5) 
and there is almost complete coverage of the ground by vegetation. Common dominant species include Themeda triandra Forssk., Poa sieberiana Spreng., Microseris walteri Gand., Dianella revoluta R.Br., Wahlenbergia stricta (R.Br.) Sweet., Arthropodium fimbriatum R.Br., Bulbine bulbosa (R.Br.) Haw., Stackhousia monogyna Labill. Small shrubs are also present in the midstorey, including Indigofera adesmiifolia A.Gray, Cassinia sifton and Acacia decora Rchb., as well as saplings of the dominant overstorey species $E u$ calyptus albens. Canopy trees include Eucalyptus albens and Brachychiton populneus (Schott \& Endl.) R.Br.

3. Grassy woodland rank understorey: this landscape occurs more than 5 years following fire, where grass tussocks have grown large and persisting forb species are present but less abundant. Themeda triandra tussocks dominate in canopy gaps with greater insolation than under tree canopies, which are dominated by Poa sieberiana. The midstorey is dominated by shrubs of Indigofera adesmiifolia, Cassinia sifton and Acacia decora, as well as saplings of the dominant overstorey species Eucalyptus albens, and canopy trees include adult Eucalyptus albens and Brachychiton populneus.

4. Callitris establishing: this landscape captures the recruitment and establishment of Callitris glaucophylla Joy Thomps. \& L.A.S.Johnson following a long absence of fire ( $>30$ years). The ground layer is dominated by Poa sieberiana, with some Themeda triandra and Microseris walteri plants. The midstorey is dominated by juvenile Callitris glaucophylla, and Eucalyptus albens, with adult Eucalyptus albens dominating the canopy.

Design and construction of the virtual landscapes and plant models

To build the virtual landscape, we focused on creating 3D models of 14 key plant species rather than modelling every species that can be found in Box Gum Grassy Woodlands. The models are not static but move and transform over time, as does the environment around them. Trees bend and wave in the breeze and fruit and flower according to the season, smouldering fires emit columns of wispy smoke, and the sun moves slowly through the virtual sky above, casting shadows along the way.

There are a number of ways to create, capture or source these models. The models comprising the virtual Box Gum Grassy Woodland were mostly crafted by $3 \mathrm{D}$ artists using specialised modelling software with close reference to photographic information. Where we made use of 3D tree modelling L-systems-now standard in 3D packages-the resulting 3D tree models needed to be altered manually because they didn't conform well to specific species' characteristics.

This project did not involve the capture of threedimensional data with stereo-photogrammetric point clouds (Guo et al. 2018), LiDAR or $360^{\circ}$ photography, because these capturing methods result in such complicated 3D models that they soon overload a computer's rendering capacity when they are multiplied in a virtual scene. There are also distinct benefits in sculpting models based on photographs from the ground up. The first is efficiency. A virtual scene commonly consists of individual geometric models that sum up to millions of polygons. Though graphics cards are constantly getting faster, sooner or later a limit is reached where too many polygons encumber a virtual reality scene so much that it can't render at interactive frame rates. This results in either dropped animation frames that can bring on VR motion sickness, or a scene that simply freezes and doesn't move at all. The models therefore must strike a balance between visual detail and geometric simplicity. For complicated scenes with many elements and moving parts, efficiency means reducing the number of polygons to a minimum and adding details with texture images without compromising the structure of the models. To add colour and details to otherwise plain and grey 3D geometry, segments of photographs taken in the field are digitally edited (cut, realigned, duplicated) and wrapped around these models as texture images. Because textures are compact raster image files, they can add a great deal of detail without increasing the number of polygons in the scene. For example, the rough, furrowed and bumpy bark of a tree in the virtual environment (Fig. 3d), is not modelled as geometry but is instead communicated by a texture mapping technique, called a 'normal map', that simulates the lighting of bumps and indentations. The virtual lighting interacts with the normal vectors and the texture colours to simulate glossy illumination 
and ambient occlusion (AO) effects (Fig. 3e). Consequently, photographs were the primary visual reference for the creation of our plant models, both
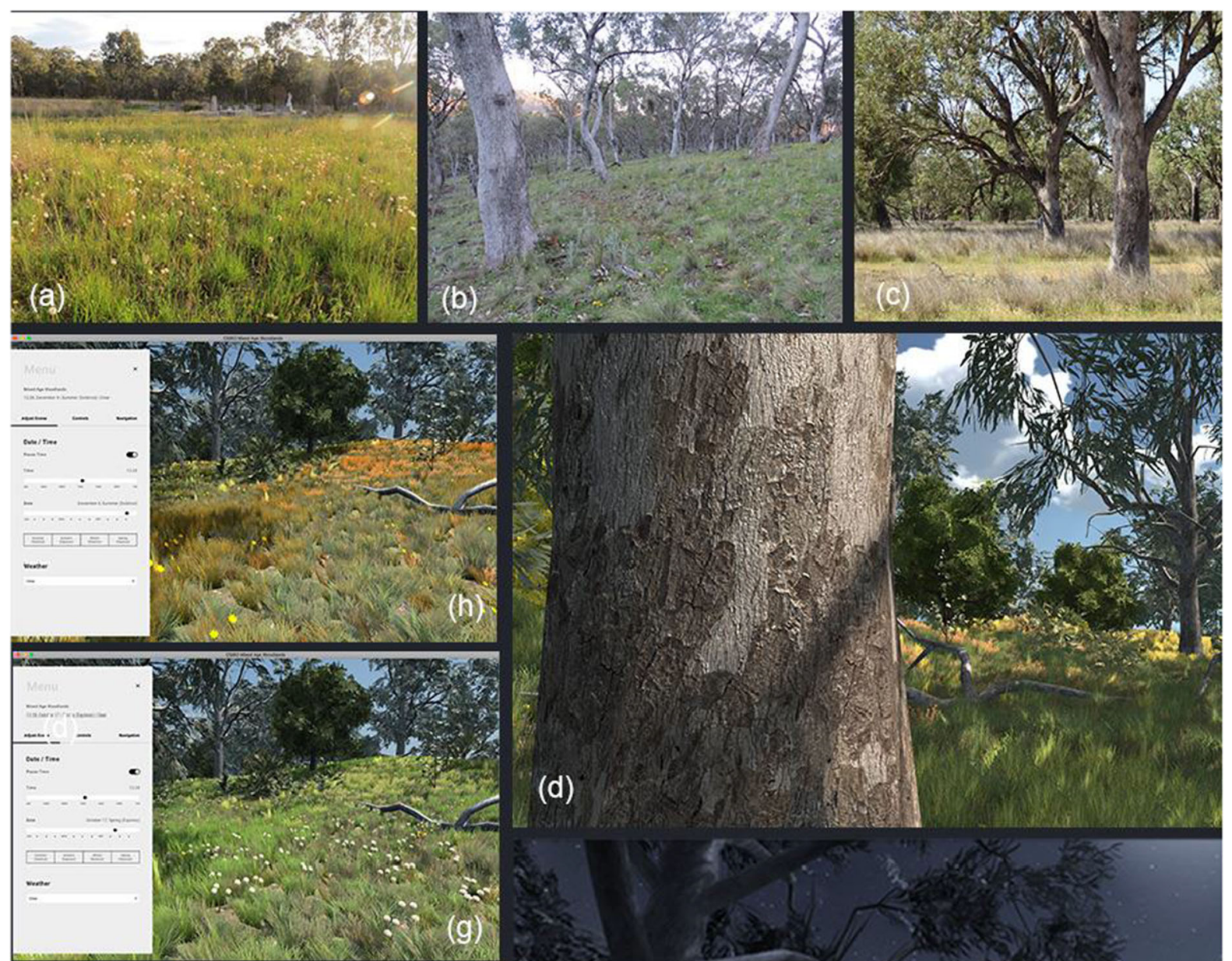

(d)

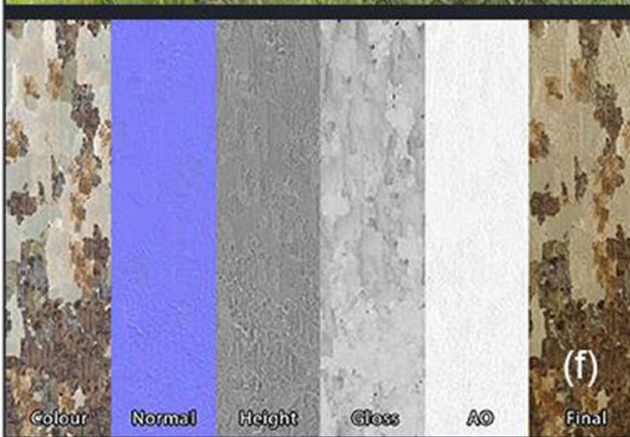

(e)

Fig. 3 Photographic references and resulting virtual scenes (clockwise from upper left) a Monteagle cemetery Yam daisy seed heads after fire, 2015 (Photo S. Prober). b White Box (Eucalyptus albens) grassy woodland near Orange, New South Wales, showing a healthy herbaceous understorey (Photo S. Prober) c White Box (Eucalyptus albens) grassy woodland in travelling stock reserve near Tamworth, New South Wales (Photo S. Prober). d A virtual White Box tree; the tree bark is textured with a photographic image wrapped around the cylindrical geometry of the tree. $\mathrm{e}$ The VR model at night under a full moon. $\mathbf{f}$ Textures derived from photography-including normal maps - that detail the 3D surface of tree bark. $\mathbf{g}$ and h Altering seasons and times of day in the interactive, screenbased application. A demonstration of the simulation and its interface can be viewed at https://youtu.be/dLHK8THukz8 
for their three-dimensional shape and the textures that added colour and details.

There was also an imperative to craft our own plant models because most of them simply did not exist in a digital form. Countless plant models native to the northern hemisphere are readily available on the internet, but Australian flora remains largely underrepresented. And, finally, there is something to be said for aesthetics; if all the models and textures are designed consistently (Fig. 1d) then the virtual world they construct is visually cohesive and believable. Believability, in this context, is not intended as verisimilitude or photorealism-as if the virtual scenes were indistinguishable from real photographs - but stylistically, in the way that an artist's series of landscape paintings might depict recognisable ecosystems in a consistent style, without necessarily replicating all of their details.

The first stage of the virtualization of these plant species involved defining specific information such as height, overall plant profile, and the shape of leaves and flowers, including changes in the size and shape of the plant and leaves at different stages of their lifecycle. For example, a Eucalyptus albens leaf has a substantially different appearance at juvenile and adult stages. The next step involved isolating reference images of the specific plant species. An optimal collection of reference images includes a range of close-up, middle distance (Fig. 3a), and wider perspective shots (Fig. 3c). The close-up images detail the plants' leaves, flowers, seeds or other finer structures, the middle-distance photos capture the profile of the plant as a whole, and photos taken from further away convey how the plant conforms within the environment, which was an important consideration for the overall scene construction.

3D textures were developed for the surfaces of the plant, and these were typically broken down into two areas. Bark for branches, the harder more solid areas of the plant, and foliage which include fine branches, petioles, leaves and flowers. The plant models were first drafted in dedicated tree modelling software, ${ }^{1}$ then their geometry was reduced, and finally textured with image maps. This resulted in a set of plant models, some with alternate textures for simulating seasonal evolution (left section of Fig. 4). The

\footnotetext{
$\overline{1 \text { SpeedTree } 8}$ for Unity, version 8.3.0.
}

textured 3D models were then imported into the Unity Engine editing environment ${ }^{2}$ and patterned over a virtual terrain of one square kilometre. The gently undulating terrain was not a rendering of a specific location but reflects a typical landscape in the study region.

Soundscapes, time and seasonality in the virtual landscape

Environmental sounds were a fundamental resource in the sonification of the proof-of-concept virtual landscape. The value of field recordings in assessing ecosystem viability and change was pioneered by Krause (Pijanowski et al. 2011). Kenwright (2020) discusses psychological concepts and immersive sound techniques for interactive environments to improve engagement and enhance the experience, and the hidden abilities of sound in interactive environments (e.g., the emotional, subconscious, and subliminal impact). In an immersive model, these sounds are also spatial, for they can be positioned to emanate from various locations in the virtual scene; some might sound close at hand, while others are distant and muted. Sound can also be animated. The sound recording of a noisy group of superb parrots (Polytelis swainsonii), for example, can be animated as passing over, or somewhere behind the viewer in the virtual environment, even though there are no animated 3D models of parrots in the scene. Figure 4 (right section) shows the wave forms of sounds (mostly bird calls), included in the virtual Box Gum Grassy Woodland landscape.

The visualisation of time was another important consideration in the creation of the virtual landscape. Within a scene the subtle passage of one moment to the next in the virtual world is marked by animation and sounds: the slowly rolling clouds, the peels of bird song, and the breeze moving through the understory. Shifting the virtual landscape from one season to the next prompted distinct changes in the environment, for example, species that were inconspicuous became immediately apparent as they came into flower. To visualise this change, we swapped between variations of the same 3D model, one in flower and the other not. We took advantage of Unity's weather simulation

\footnotetext{
${ }^{2}$ Unity Engine is a content authoring and rendering engine software by Unity Technologies: unity.com.
} 


\begin{tabular}{|c|c|}
\hline Species & Common name \\
\hline Acacia decora & Western silver wattle \\
\hline $\begin{array}{l}\text { Arthropodium } \\
\text { fimbriatum }\end{array}$ & Chocolate lily \\
\hline $\begin{array}{l}\text { Brachychiton } \\
\text { populneus }\end{array}$ & Kurrajong \\
\hline Bulbine bulbosa & Bulbine lily \\
\hline Collitris gloucophyllo & White cypress-pine \\
\hline Cassinia sifton & Drooping cassinia \\
\hline Dianella revoluta & Blue flax-lily \\
\hline Eucalyptus albens & White box \\
\hline $\begin{array}{l}\text { Indigofera } \\
\text { adesmiifolia }\end{array}$ & Tick indigo \\
\hline Microseris walteri & Yam daisy \\
\hline Poa sieberiana & Grey tussock-grass \\
\hline $\begin{array}{l}\text { Stackhousia } \\
\text { monogyna }\end{array}$ & Creamy candles \\
\hline Themeda triandra & Kangaroo grass \\
\hline Wahlenbergia stricta & Tall bluebell \\
\hline
\end{tabular}

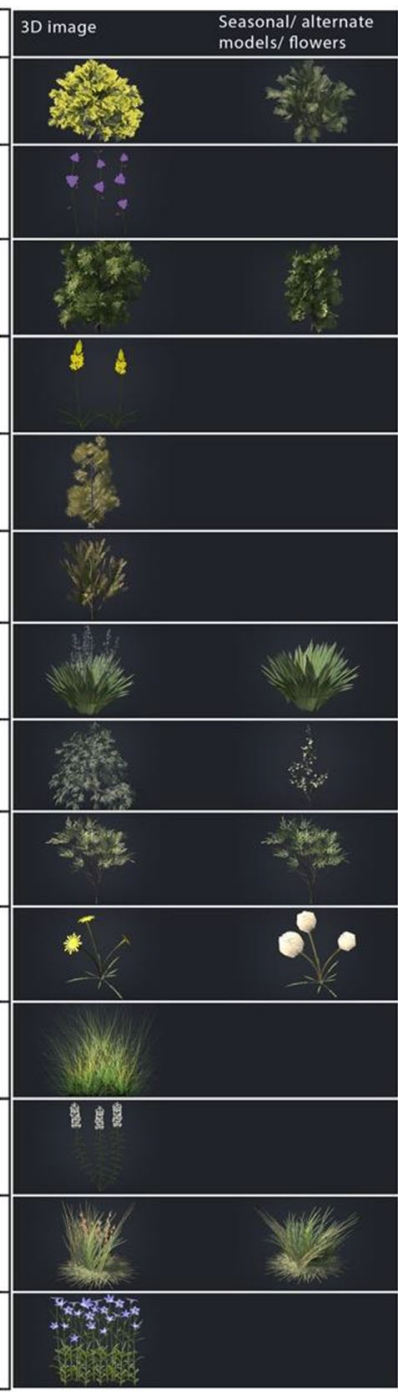

\begin{tabular}{|c|c|c|}
\hline Species & Common name & Wave form \\
\hline $\begin{array}{l}\text { Callocephalon } \\
\text { fimbriatum }\end{array}$ & Gang-gang cockatoo & $\theta$ \\
\hline $\begin{array}{l}\text { Anthochaera } \\
\text { carunculata }\end{array}$ & Red wattlebird & \\
\hline Merops ornatus & Rainbow bee-eater & \\
\hline $\begin{array}{l}\text { Cacomantis } \\
\text { fabelliformis }\end{array}$ & Fan-tailed cuckoo & \\
\hline $\begin{array}{l}\text { Platycercus } \\
\text { eximius }\end{array}$ & Eastern rosella & 4 \\
\hline $\begin{array}{l}\text { Petroica } \\
\text { phoenicea }\end{array}$ & Flame robin & \\
\hline $\begin{array}{l}\text { Corvus } \\
\text { coronoides }\end{array}$ & Australian raven & \\
\hline $\begin{array}{l}\text { Manorina } \\
\text { melanocephala }\end{array}$ & Noisy miner & \\
\hline Geopelia placida & Peaceful dove & $-m$ \\
\hline Parvipsitta pusilla & Little lorikeet & - \\
\hline Ninox boobook & Southern boobook & 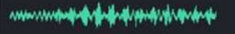 \\
\hline Petaurus breviceps & Sugar glider & \\
\hline
\end{tabular}

Fig. 4 The 14 key species of Box Gum Grassy Woodland modelled in 3D with seasonal variations, (left) and sounds (right) included in the virtual landscape. Species are ordered alphabetically

system to create a continuum that spanned the entire year. Using an interactive dashboard (Fig. 5g, 5h), the user can adjust sliders for the time of the day and month and see the model and lighting alter accordingly. In order to perceive details in a nocturnal scene, we trialled a clear, moonlit sky with highly contrasted shadows (Fig. 3e). and we matched the moonlit woodland with a soundscape punctuated by sharp, chirping barks of sugar gliders (Petaurus breviceps) and the sonorous calls of the southern boobook owl (Ninox boobook).

Due to the catastrophic bushfires that impacted south-eastern Australia in late 2019, we decided to focus on creating VR experiences based upon the 'mixed-age woodlands' (framed in Fig. 2b) and did not include a post-fire landscape. The reason for this was a concern that participants involved in the evaluation of the virtual landscape (many of whom had directly experienced the bushfires) could have had a detrimental reaction to an immersive VR experience of burnt landscapes. The 'mixed-age woodlands' scene portrayed different seasons, lighting conditions, and ambient soundscapes. We selected three examples with the greatest visual contrast. These three examples were later exported to form the immersive VR experience described below (Fig. 5). 


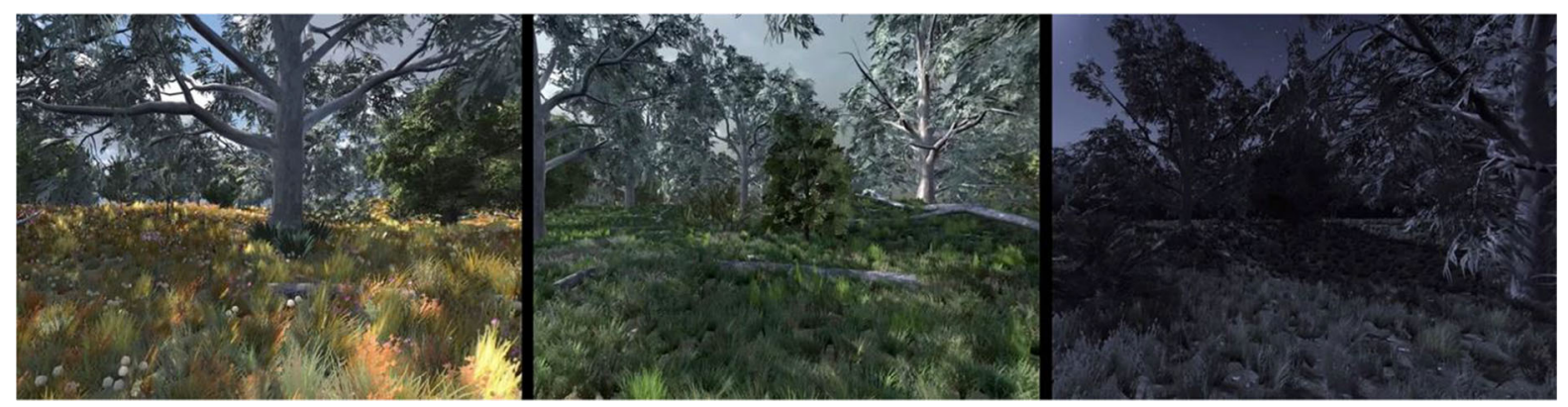

Fig. 5 Screenshots of the three animated, $360^{\circ}$ panoramic visualisations that study participants experienced while seated with VR headsets on. Each scene depicts the same landscape in different seasons and times of the day. From left to right: a

Evaluation of the virtual landscape

We conducted an empirical evaluation of the virtual reality Box Gum Grassy Woodland ecosystem adapting a heuristic evaluation approach (Nielsen 1993). The specific aims of this evaluation were to (a) determine whether ecologists and land managers in biodiversity conservation see potential in using VR for communicating and visualising natural environments, (b) identify potential use cases of virtual ecology applications, (c) collect feedback in regard to immersion and believability of our virtual ecology simulation, and (d) gather suggestions for improvements from experts familiar with the modelled ecosystem.

\section{Participants}

We organised a series of meetings with domain experts at the Department of Agriculture, Water and the Environment in Canberra, Australia, which took place on the 6th of March 2020. Twenty-seven experts participated. Our experts, in contrast to studies with the general public or undergraduate students, had a diverse set of expertise all relevant to ecological questions surrounding the environment, such as environmental policy development, program/project management and compliance in the Department of Agriculture, Water and the Environment, plant ecology, evolutionary biology and paleoecology.

\section{Procedure}

We ran four meetings with 4 to 15 participants each, consisting of a presentation followed by an empirical summer scene, a winter scene, and an autumn night scene showing the moon and stars. The 360-degree video can be viewed at https://youtu.be/n_bTonNWqvg

evaluation by the domain experts of an immersive virtual ecology application viewed with VR headsets. The presentation consisted of an introduction to the project and ecosystem modelling, then focused on modelling for VR, and finished with an outlook of how future virtual ecology visualisations could be used to visualise the output of ecosystem models. Our presentation overviewed all four scenes (Fig. 2b) from the Box Gum Grassy Woodlands simulation. However, for the evaluation, participants were shown the three 360-degree panoramic visualisations of the 'mixed-age woodlands' scene depicted in Fig. 5 in a VR headset. The immersive experience lasted for 3 to $5 \mathrm{~min}$, and then the participants completed a questionnaire. The questionnaire first asked about the professional role of the participants, then asked nine questions, which were answered with written replies. The questionnaire is included in Supplementary Information and focused on four main themes: credibility/plausibility, accuracy/completeness, presence/ immersion, and applications/users. Participants were asked to answer these questions with respect to the VR application they had viewed but with an understanding of the context provided in the presentation, which, as mentioned above, showed additional scenes, including an immediate post-fire simulation.

\section{Materials: hardware and software}

The interactive application described above (Fig. 3h, g) was initially designed for VR headsets and handheld controllers, using a tracking system that allowed users to move around in virtual space. However, such a setup would have necessitated a protracted evaluation 
of the immersive experience by each participant in turn, which was unrealistic given the number of participants, the spatial constraints, and the available time. Instead, we prepared a VR application that played immersive scenes viewed from a fixed position. We used several Oculus Go all-in-one headsets, because they do not need to be tethered to an external computer. They offered $1280 \times 1440$ pixels per eye with a field of view of approximately $100^{\circ}$. These headsets used 3-degrees-of-freedom tracking, which is suitable for seated viewing.

To accommodate a relatively large group of participants, as described above, we rendered a $360^{\circ}$ video from the VR proof-of-concept virtual landscape (Fig. 5). ${ }^{3}$ Instead of a fully interactive VR experience with headset and controller tracking, these animated $360^{\circ}$ panoramic visualisations allowed the participants to look around the virtual environment while seated with the headsets on. Each scene played for $45 \mathrm{~s}$, resulting in a total video length of 2:15 $\mathrm{min}$. The video played in a loop, and the three scenes faded in and out from a black background. The scenes contained animated elements such as tree branches and grasses swaying in the wind, and occasional clusters of flying insects (implemented with particle effects) in the daylight scenes. Each scene had its own spatialized soundscape where, for example, participants could discern bird calls coming from behind them, or from somewhere off to their right, depending on where they turned their heads to look around. Observing and listening were the key interactions; besides switching between scenes with a handheld controller, no other type of interaction was possible. The scenes were scaled relative to the size of an average person and appeared at real size.

\section{Evaluation results}

Results from the evaluation of the VR simulation are separated below into the four theme areas.

\section{Credibility/plausibility}

The first question (1a, Supplementary Information) asked participants to comment on how believable the

\footnotetext{
3 The 360-degree video is accessible at https://youtu.be/n_ bTonNWqvg.
}

different plant species were. 24 participants (88\%) thought that plants were believable, two expressed neutral feelings, and one participant did not find the plants to be believable (this participant was not able to wear glasses with the headset and accordingly reported poor vision).

\section{Accuracy/completeness}

The following two questions asked, "what would we need to change to make the VR visualisation more accurate?" (Question 1b, Supplementary Information) and "is there anything missing, something you expect to see or hear that isn't included?" (Question 1c, Supplementary Information). Participants suggested a large variety of improvements. From questions $1 \mathrm{a}, 1 \mathrm{~b}$ and 1c, we compiled categories addressing the features participants thought should be improved or added (Fig. 6). We identified the following themes: $35 \%$ of suggestions focused on adding or altering fauna; the most suggested faunal groups were birds, mammals (including humans) and invertebrates (mainly insects). Insects and birds were mentioned most often, possibly because the bird sounds in the summer scene and the insect sounds in the autumn night scene triggered these associations. Suggestions for improving the vegetation $(32 \%)$ were almost as common. We received suggestions for improving the understory (from 3 participants), the shape of trees and eucalypt leaves ( 3 participants) and improving ground cover (3 participants). A further three participants expressed interest in natural imperfections, such as adding tree hollows and ground litter and others proposed more diverse "stages of growth of the same plant" or mentioned the desirability of a "diversity of mixes and patchiness of spatial mixes". Three participants suggested enhancing the soundscape. Overall, diversity, natural imperfections and details were deemed important in the visualizations to create an immersive experience.

\section{Presence/immersion}

Three questions asked about the feeling of being present in the VR scenes and perceived immersion. To question 2a (Supplementary Information) "Did you feel as if you were 'inside' or 'present' in a simulated environment, instead of, for example, looking at a video or a photo?" 21 of the 27 participants (78\%) answered that they felt immersed or very immersed. 


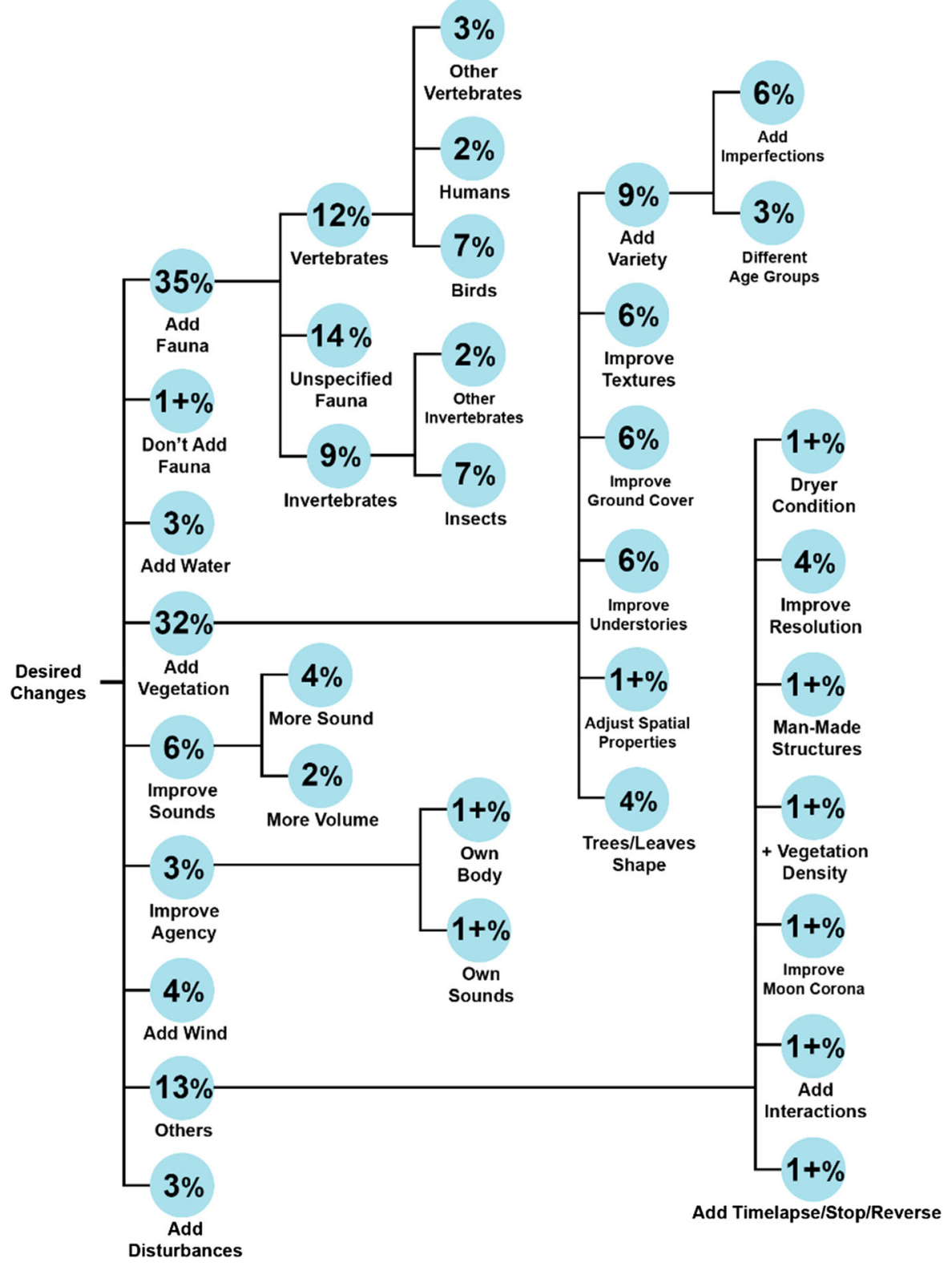

Fig. 6 Improvements to the virtual ecology application suggested by the 27 study participants. Percent values are relative to the total number of suggested improvements

The other six participants commented that it "felt a little like a 3D photo due to limited movement" or similar, or found that technical limitations, such as the limited screen resolution prevented deep immersion. To the question $2 b$ (Supplementary Information) "Did you feel that you wanted to interact with the environment, i.e., select from on-screen menus, walk around, pick up and drop objects? Or was just observing and listening sufficient?" $83 \%$ of participants commented that they wanted to interact with the scene, while 17\% thought that "just observing and listening [was] sufficient". 35\% suggested adding the ability to move through the forest scene (a functionality that we did not permit, as described above). Haptic feedback $(14 \%)$, a menu interface $(7 \%)$, interaction with virtual objects (7\%), and the ability to collect items (3.5\%) 
were also suggested. We also asked participants what they thought triggered a sense of immersion with question 2c (Supplementary Information): "Which of the three-dimensional visuals, environmental lighting and sound effects helped build an immersive experience? Did any of these interrupt your sense of immersion?" 12 of the 27 participants (44\%) thought that the soundscape helped create an immersive experience, seven (26\%) thought that the lighting and shading effects created an immersive experience, and four (15\%) mentioned that they enjoyed the night sky with stars. Four participants commented positively on the animation of plants due to wind and the moving clouds, but two thought that the movement was too repetitive or not subtle enough. A small number of participants reported that their immersion was negatively affected by small discrepancies or technical inconsistencies.

\section{Applications/users}

The last three questions asked about (Question 3a, Supplementary Information) potential application domains of immersive visualisation for the communication of ecosystems dynamics, (Question 3b, Supplementary Information) applications that are particularly useful and impactful, and (Question 3c, Supplementary Information) which users would profit most. These questions were included to collect application domains of immersive VR that the participants thought were particularly promising. Across all three questions, 19 participants $(70 \%)$ replied that education, for example, in biology and sustainability studies in the Australian high school curriculum, or in conservation and ecology studies at university, is a valuable application domain or that students at various academic levels are particularly likely to profit. 18 (67\%) commented that VR would be useful for decision makers in land management and environmental policy, as well as landowners, farmers, conservation ecologists, etc. who are involved in decision making or restoration of landscapes. Four (15\%) mentioned the potential to use VR for engagement with indigenous communities and traditional landowners.

\section{Discussion}

Our VR proof-of-concept visualisation extends the conceptual box-and-arrow diagrams of the AusEcoModels framework into an experiential format. We received positive feedback from the 27 study participants on the virtual Box Gum Grassy Woodlands landscape. Some comments were enthusiastic, and a vast majority of participants agreed that they felt immersed in the VR scene. When creating the immersive landscape, the focus was on a plausible rendition of trees. We seem to have been successful in this respect, because $88 \%$ of participants found the scene to be believable. About a third of all participants suggested adding fauna; the scenes currently only contained flying insects. An important outcome from the survey was that about one third of participants found that the scene was "too clean" and homogenous by suggesting a more diverse understory and textures, increasing ground cover, adding imperfections and varying the age and spatial distribution of plant models. Education and land management decisions were suggested as the main application domains. This feedback is encouraging, as expert participants perceived immersive VR landscapes as a potentially useful tool to communicate indicators of ecological condition and how these may change across managed landscapes. For policy makers or land managers, testing virtual reality scenarios of different land management options could be used to improve decision making capacity.

One aspect that we did not query the participants about was the capacity for visualising landscape change over time in the model. Our visualisation attempted to distil a single expression of Box Gum Grassy Woodlands as discrete moments in time. Temporal shifts were implicit, but they were all at an experiential scale, with the light and soundscapes changing through the day and night, and the flowering of the grasses, shrubs and trees through the seasons. Additional scenes were being developed as part of the simulation, but it wasn't appropriate to prepare these as VR experiences, and so the participants didn't experience the disturbance and recovery processes associated with fire that operate over years and decades. At present, our simulation deals only with a single year, and there is no functionality for conveying consecutive, or accumulating, years between a scene and another. This is an area for further development. 
The White Box Gum Grassy Woodlands modelled here are an endangered ecological community. The VR approach provides a communication tool for endangered ecological communities where, in many cases, the original ecosystem cannot be located, and videos or photographs demonstrating its dynamics (e.g. fire responses) are impossible to acquire. In modelling the landscape dynamics of Box Gum Grassy Woodlands, we used expert knowledge and published literature describing the structure, function, composition and disturbance dynamics of this ecosystem in its reference state. However, it was in discussions with workshop participants after our evaluation was concluded that new perspectives arose. Several people pointed out that what we had modelled might in fact already be historical, because the landscapes as we had depicted them might no longer exist. In modelling the present, and in approaching a vision of simulated futures, we had also, unintentionally, created an archive of the past. But there is value in this exploration nevertheless.

Reference states of many ecosystems are rapidly being transformed by contemporary land use and climate change, and they are neither a feasible nor practical goal for current natural resource management activities (Palmer et al. 1997; Swetnam et al. 1999; Hobbs 2007). However, models of ecosystem reference states provide a guide to understanding ecological memories and legacies (Swetnam et al. 1999; Peterson 2002) which can inform current understanding of observed ecosystem behaviour. Such an understanding is critical for predictions of the characteristics of future ecosystem states, given the rapid transformation and homogenisation of ecosystems impacted by changes in climate, land use, and land management. For ecosystem management interventions to be effective there is a need to acknowledge and learn from these ecological legacies and communicate them in a way that can be understood by nonexperts.

There is also value in approaching the visual reconstruction of a vanished landscape for its own sake, drawing upon the forensics of both scientific and art historical evidence so that we might apprehend, and perhaps also hear, what has been lost. In Australia, much of what we have come to regard as enduring 'natural' landscapes are often degraded, impoverished versions of the ones that came before them. In examining the intergenerational memory loss of
Australian landscapes since European colonisation, pictorial references from art galleries and museums offer a guiding vision. The paintings of Eugene von Guérard in the mid-1800s (Fox 2012) portray, in the aesthetics of the Romantic movement, landscapes on the cusp of tremendous change. Replete with open woodlands, grassy patches and pathways, and abundant wildlife, these landscapes had been maintained by indigenous Australians for millennia (Gammage 2013). Reconstructing ancient landscapes from paleoecology is another fascinating line of investigation, especially where pollen records stretch back thousands of years (Haberle 2005). These excursions into recent and deep history are just a few of the many possible applications of reconstructed ecosystems modelled for Immersive VR.

Nevertheless, the challenges of the present, and particularly of the near future, remain paramount. How are we to apprehend the possible futures of these landscapes? One path forward is the exploration of contrasting scenarios through the simulation of virtual landscapes. If one was to burn down a real forest to watch it regenerate, the forest may never recover. Or it may take longer to recover than the observer's lifetime. In a virtual model, on the other hand, you can burn a forest repeatedly and observe it regenerating over virtual decades or centuries (Green and Chandler 2014). Virtual reality simulations can take into account the possible or probable constitution of the landscape in reference to the impact of fire regimes, invasive species, cattle stocking rates, or climate change. Because the viewer is immersed within them, such explicitly visual and sonic virtual simulations also convey the qualities of a dynamic landscape more directly than abstract visualizations, such as maps, diagrams and graphs.

To comprehensively model forest dynamics requires the coordinated efforts of computer scientists, biologists and mathematicians. So far, biological simulations and visualisations seem to have been separate endeavours (Favorskaya and Jain 2017). Future research might soon attempt the simulation of organic, growing virtual ecosystems that capture the dynamics of forest, soil, hydrological, atmospheric systems and human impacts. This study however, leans more toward experiential ecology, and the evidence-based creation of virtual ecosystem models, which requires an iterative and serendipitous approach. Future iterations of this research, including 
its extension to incorporate other Australian terrestrial ecosystems, will likely be guided by questions, such as the ones following here, that emerged during the course of its creation. How much scene detail is needed to portray a landscape or all Australian landscapes? How do the 3D models fit together to suggest a cohesive, albeit simulated, reality? How can a simplified version of reality derived from a limited range of geometry and environmental sounds, construct a believable illusion of a living ecosystem? How can this be made dynamic, to shift through seasons and passage of the day? How might it change over longer spans of time, in line with ecological monitoring data?

\section{Conclusion}

Our construction and evaluation of the box-gum grassy woodland visualisation indicated that immersive VR offers a promising approach to facilitating an understanding of the dynamics of ecological communities by practitioners and policymakers. More research is needed to demonstrate effectiveness for improving conservation management and policy outcomes; but our results suggest a way forward for communicating and hence contributing to management of the biodiversity crisis. The increasing availability of ecosystem dynamic models (e.g., through the AusEcoModels Framework and related programs) provide a structured framework along with detailed ecological knowledge that can underpin development of such models. A major constraint remains the time and resources required to prepare realistic 3D models and soundscapes to represent real-world ecological communities. To overcome this, we suggest global or national collaborations are needed to build opensource libraries of visually compatible fauna and flora 3D models, along with field recordings of sounds, especially bird calls, but also insects, mammals and frogs. To enable more rapid creation of VR landscapes, it will also be of interest to explore the minimum number of species or objects needed to create a believable landscape, and how this number changes between ecosystems.

Since conducting our empirical evaluation one year ago, we have witnessed substantial advancements of immersive technologies. For example, the VR headset used in our study was discontinued and its successor is already in its second iteration. This illustrates that immersive experiences are rapidly becoming a medium of mass communication that is accessible to a growing number of researchers, educators, decisionmakers, and the general public. Empirical studies like the one reported here as well as a growing number of studies by landscape visualization specialists (Edler et al. 2020) and place-based scientists (Klippel et al. 2019) are instrumental in driving our understanding of how immersive experiences can become a powerful tool for creating both intellectual and visceral insights into variability and dynamics of ecosystems. In view of an accelerating biodiversity crisis, VR landscapes have the potential to not only help land managers and policymakers make better decisions, but also to engage and inform students of ecology, and citizens, living in increasingly urban environments.

Acknowledgements We would like to acknowledge the input of participants to the evaluation of the proof-of-concept virtual landscape. The authors thank Rick Laird, Monash University, Melbourne, Australia, for developing an early iteration of a virtual Box Gum Grassy Woodland, Sue McIntyre, CSIRO Land and Water, Canberra, Australia, and Justin Baker, CSIRO Information Management \& Technology, Clayton, Victoria, Australia for commenting on a draft version of the manuscript, and Su-Yiin Lai, Monash University, Melbourne, Australia for transcribing the manuscript questionnaires and her help with developing the VR proof of concept.

Author contribution The virtual reality proof-of-concept was conceived and designed by TC, AER, BJ, MN, SMP and FW. $\mathrm{MN}$ created three-dimensional models, the virtual scene and the user interface. AER, SMP and TC provided feedback on the shape and appearance of models. TC and BJ provided feedback on lightning and the user interface and tested with virtual reality headsets. BJ, AER, AK and TC designed the user study questionnaire; FD organised meetings with experts; AER, TC and $\mathrm{BJ}$ gave introductory presentations at the meetings, ran the VR demos, and conducted the user study. BJ, JH and $\mathrm{AK}$ collected and analysed the user study data. TC, AER, BJ, SMP, $\mathrm{FD}, \mathrm{JH}$, and $\mathrm{AK}$ wrote this paper.

Funding We acknowledge funding provided by CSIRO Australia through an eResearch grant to Richards and Prober, and funding for the Australian Ecosystem Models Framework project provided by CSIRO and the Australian Government Department of Agriculture, Water and the Environment (2016-2018). Chandler, Jenny and Klippel acknowledge funding from the Monash-Pennsylvania State University Collaboration Development Program, 2018-2019.

Data availability The generated three-dimensional models are available for non-commercial applications from the corresponding author on reasonable request. 


\section{Declarations}

Conflict of interest All authors have no financial or proprietary interests in any material discussed in this article.

Ethical approval This work was undertaken in accordance with ethical principles using methodology approved by the Monash University Human Research Ethics Committee (project number 23450 "Virtual Ecology") and by CSIRO's Social Science Human Research Ethics Committee in accordance with the National Statement on Ethical Conduct in Human Research (2007): ethics approval 013/20.

Informed consent Consent statement included at beginning of questionnaire handed out to study participants: I have been asked to take part in the Monash University research project specified above. I have read and understood the Explanatory Statement and I hereby consent to participate in this project. I consent to the following: I am at least 18 years of age and agree to participate in the study. Yes - No. My participation is voluntary, and I can withdraw at any stage of the survey. Yes - No. Any data that the researchers extract from the study for use in reports or published findings will not contain names or identifying characteristics. Yes - No. Name and date: . All authors have consented to publication of this material.

Open Access This article is licensed under a Creative Commons Attribution 4.0 International License, which permits use, sharing, adaptation, distribution and reproduction in any medium or format, as long as you give appropriate credit to the original author(s) and the source, provide a link to the Creative Commons licence, and indicate if changes were made. The images or other third party material in this article are included in the article's Creative Commons licence, unless indicated otherwise in a credit line to the material. If material is not included in the article's Creative Commons licence and your intended use is not permitted by statutory regulation or exceeds the permitted use, you will need to obtain permission directly from the copyright holder. To view a copy of this licence, visit http://creativecommons.org/licenses/by/4.0/.

\section{References}

Bestelmeyer BT, Ash A, Brown JR, Densambuu B, FernándezGiménez M, Johanson J, Levi M, Lopez D, Peinetti R, Rumpff L (2017) State and transition models: theory, applications, and challenges. Rangeland systems. Springer, Cham, pp 303-345

Boudon F, Meyer A, Godin C (2006) Survey on computer representations of trees for realistic and efficient rendering. Technical report

Brondizio ES, Settele J, Díaz S, Ngo HT (2019) Global assessment report on biodiversity and ecosystem services of the Intergovernmental Science-Policy Platform on Biodiversity and Ecosystem Services. IPBES secretariat, Bonn
Chandler T, Clulow A (2020) Modeling Virtual Angkor: an evolutionary approach to a single urban space. IEEE Comput Graphics Appl 40(3):9-16

Cheal D (2010) Growth stages and tolerable fire intervals for Victoria's native vegetation data sets. Fire and Adaptive Management. Department of Sustainability and Environment, Melbourne, p 257.

Dede C (2009) Immersive interfaces for engagement and learning. Science 323(5910):66-69

Department of Environment, Climate Change and Water NSW (2010). National recovery plan for White Box -Yellow Box -Blakely's Red Gum Grassy Woodland and Derived Native Grassland. C. C. a. W. Department of Environment, NSW, Sydney, Department of Environment, Climate Change and Water NSW, p 90.

Edler D, Kühne O, Jenal C (2020) Modern approaches to the visualization of landscapes - an introduction. Modern approaches to the visualization of landscapes. Springer, New York, pp 3-15

Fabrika M, Valent P, Scheer L' (2018) Thinning trainer based on forest-growth model, virtual reality and computer-aided virtual environment. Environ Model Softw 100:11-23

Favorskaya MN, Jain LC (2017) Handbook on advances in remote sensing and geographic information systems. Springer, New York

Fox P (2012) Eugene von Guérard: Nature Revealed. Aust Hist Stud 43(2):303-311

Gammage B (2013) The biggest estate on earth.

Green DG, Chandler T (2014) Virtual ecologies and environments. The Oxford handbook of virtuality.

Guo J, Xu S, Yan D-M, Cheng Z, Jaeger M, Zhang X (2018) Realistic procedural plant modeling from multiple view images. IEEE Trans Visual Comput Graph 26:1372-1384

Haberle SG (2005) A 23,000-yr pollen record from Lake Euramoo, wet tropics of NE Queensland, Australia. Quatern Res 64(3):343-356

Hobbs RJ (2007) Setting effective and realistic restoration goals: key directions for research. Restor Ecol 15(2):354-357

Hruby F, Ressl R, de la Borbolla Del Valle G (2019) Geovisualization with immersive virtual environments in theory and practice. Int J Digital Earth 12(2):123-136

Huang J, Lucash MS, Scheller RM, Klippel A (2019) Visualizing Ecological Data in Virtual Reality. In: 2019 IEEE conference on virtual reality and 3D user interfaces (VR), IEEE.

Huang J, Lucash MS, Scheller RM, Klippel A (2020) Walking through the forests of the future: using data-driven virtual reality to visualize forests under climate change. Int $\mathbf{J}$ Geograph Inf Sci 35:1155-1178

Kandziora M, Burkhard B, Müller F (2013) Interactions of ecosystem properties, ecosystem integrity and ecosystem service indicators - a theoretical matrix exercise. Ecol Ind 28:54-78

Kay JJ (1991) A nonequilibrium thermodynamic framework for discussing ecosystem integrity. Environ Manage 15(4):483-495

Kenwright B (2020) There's more to sound than meets the ear: sound in interactive environments. IEEE Comput Graph Appl 40:62-70 
Klippel A, Zhao J, Oprean D, Wallgrün JO, Stubbs C, La Femina P, Jackson KL (2019) The value of being there: toward a science of immersive virtual field trips. Virtual Reality 24:753-770

Kohek Š, Strnad D (2018) Interactive large-scale procedural forest construction and visualization based on particle flow simulation. Computer graphics forum. Wiley, New York

Lindenmayer A (1968) Mathematical models for cellular interactions in development II. Simple and branching filaments with two-sided inputs. J Theor Biol 18(3):300-315

McCormack J (2004) Generative modelling with timed L-systems. Design computing and cognition'04. Springer, New York, pp 157-175

McIntyre S, Lavorel S (2007) A conceptual model of land use effects on the structure and function of herbaceous vegetation. Agr Ecosyst Environ 119(1-2):11-21

Milgram P, Kishino F (1994) A taxonomy of mixed reality visual displays. IEICE Trans Inf Syst 77(12):1321-1329

Neubert B, Pirk S, Deussen O, Dachsbacher C (2011) Improved model-and view-dependent pruning of large botanical scenes. Computer graphics forum. Wiley, New York

Newbold T, Hudson LN, Arnell AP et al (2016) Has land use pushed terrestrial biodiversity beyond the planetary boundary? A global assessment. Science 353:288-291

Nielsen J (1993) Iterative user-interface design. Computer 26(11):32-41

Norton BG (1992) A new paradigm for environmental management. Ecosyst Health 20:633-638

Palmer MA, Ambrose RF, Poff NL (1997) Ecological theory and community restoration ecology. Restor Ecol 5(4):291-300

Pecl GT, Araújo MB, Bell JD, Blanchard J, Bonebrake TC, Chen I-C, Clark TD, Colwell RK, Danielsen F, Evengård B (2017) Biodiversity redistribution under climate change: impacts on ecosystems and human well-being. Science 355(6332):e9214

Peterson GD (2002) Contagious disturbance, ecological memory, and the emergence of landscape pattern. Ecosystems 5(4):329-338

Pijanowski BC, Villanueva-Rivera LJ, Dumyahn SL, Farina A, Krause BL, Napoletano BM, Gage SH, Pieretti N (2011) Soundscape ecology: the science of sound in the landscape. Bioscience 61(3):203-216

Prober S, Thiele K (2004) Fire recovery vegetation monitoring in White Box-White Cypress Pine woodlands of East Gippsland. Arthur Rylah Institute for Environmental Research technical series report.

Prober SM, H J, Cook GD, Gosper CR, Yates CJ, Richards AE (2021) Eucalypt woodlands. C. L. a. Water, Australia, CSIRO

Prober SM, Stol J, Piper M, Gupta V, Cunningham SA (2014) Towards climate-resilient restoration in mesic eucalypt woodlands: characterizing topsoil biophysical condition in different degradation states. Plant Soil 383(1):231-244

Prober SM, Thiele K (1995) Conservation of the grassy white box woodlands: relative contributions of size and disturbance to floristic composition and diversity of remnants. Aust J Bot 43(4):349-366
Prober SM, Thiele KR (2005) Restoring Australia's temperate grasslands and grassy woodlands: integrating function and diversity. Ecol Manag Restor 6(1):16-27

Prober SM, Thiele KR, Lunt ID (2002) Identifying ecological barriers to restoration in temperate grassy woodlands: soil changes associated with different degradation states. Aust J Bot 50(6):699-712

Richards A, Dickson F, Williams K, Cook G, Roxburgh S, Murphy H, Doherty M, Warnick A, Metcalfe D, Prober S (2020) The Australian ecosystem models framework project: a conceptual framework. CSIRO. https://doi.org/10. 25919/f61q-1386

Scheffers BR, De Meester L, Bridge TC, Hoffmann AA, Pandolfi JM, Corlett RT, Butchart SH, Pearce-Kelly P, Kovacs KM, Dudgeon D Pacifici M (2016) The broad footprint of climate change from genes to biomes to people. Science 354(6313)

Slater M, Sanchez-Vives M (2016) Enhancing our lives with immersive virtual reality. Front. Robot AI 3:74

Steffen W, Richardson K, Rockström J, Cornell SE, Fetzer I, Bennett EM, Biggs R, Carpenter SR, De Vries W, De Wit CA, Folke C (2015) Planetary boundaries: guiding human development on a changingplanet. Science 347(6223)

Stol J, Prober SM (2015) Jewels in the landscape: Managing very high conservation value ground layers in Box-Gum Grassy Woodlands. CSIRO Land and Water Flagship, Canberra

Stringham TK, Krueger WC, Shaver PL (2003) State and transition modeling: an ecological process approach.

Swetnam TW, Allen CD, Betancourt JL (1999) Applied historical ecology: using the past to manage for the future. Ecol Appl 9(4):1189-1206

Wallgrün JO, Masrur A, Zhao J, Taylor A, Knapp E, Chang J, Klippel A (2019) Low-cost VR applications to experience real word places anytime, anywhere, and with anyone. 2019 IEEE 5th workshop on everyday virtual reality (WEVR), IEEE.

Wallgrün JO, Zhao J, Sajjadi P, Oprean D, Murphy TB, Baka J, Klippel A (2019) For the many, not the one: designing lowcost joint vr experiences for place-based learning. In: International conference on virtual reality and augmented reality. Springer, Berlin.

Westoby M, Walker B, Noy-Meir I (1989) Opportunistic management for rangelands not at equilibrium. Rangel Ecol Manag 42(4):266-274

Zhang X, Bao G, Meng W, Jaeger M, Li H, Deussen O, Chen B (2017) Tree branch level of detail models for forest navigation. Computer graphics forum. Wiley, New York

Zhao J, Klippel A (2019) Scale-unexplored opportunities for immersive technologies in place-based learning. In: IEEE conference on virtual reality and 3D user interfaces (VR). IEEE

Publisher's Note Springer Nature remains neutral with regard to jurisdictional claims in published maps and institutional affiliations. 